\title{
EDITORIAL
}

\section{Realización de actividades científicas y tecnológicas en la población escolar y su aporte en el desarrollo científico regional}

Realizar investigación en Chile no es tarea fácil y menos para las regiones más alejadas del centro del país. Además de competir por los recursos financieros con las regiones del centro y sur, nos afecta una menor disponibilidad del capital humano especializado que muchas veces opta por los atractivos que le brinda la aglomeración científica y tecnológica que existe en las regiones más densas del país. En este sentido, colaborar en la formación científica y tecnológica de los niños y niñas en edad escolar, es una tarea clave para mejorar las condiciones de competitividad regional. Sin embargo, en el ambiente académico, realizar acciones de este tipo, suele estar menos valorado que la publicación de un trabajo en una revista con un índice de alto impacto. Es por eso que las acciones de divulgación científica a la comunidad no especialista, dependen de las voluntades en tiempo y convicción personal de los investigadores más que de una política de la universidad.

Sabemos, por la evidencia empírica, que mejorar las condiciones de competitividad de una región y/o territorio pasa por centrarse en valorar, retener y atraer a los suyos apostando a su formación en tempranas edades. Y aquí, los investigadores podemos y debemos colaborar en el fortalecimiento del sistema educativo con acciones en ciencia, tecnología e innovación para alcanzar un desarrollo sustentable basado en el conocimiento y la formación de capital humano regional.

En la región del extremo norte de Chile, el programa EXPLORA de la Comisión Nacional de Investigación Científica y Tecnológica CONICYT (próximamente Ministerio de Ciencia y Tecnología), lleva adelante una serie de actividades entre la población escolar para promover el interés por la ciencia y la tecnología, mostrando el trabajo científico local, los beneficios que trae para las personas y el territorio pero, por sobre todo; mostrando a la investigación como una opción profesional. Existen numerosos ejemplos de investigación escolar donde la participación conjunta de científicos, estudiantes y sus profesores han resultado en trabajos de investigación muy interesantes y novedosos. Incluso algunos de esos trabajos han sido premiados en los congresos regionales/nacionales e internacionales de ciencia y tecnología. Muchos de ellos han permitido el traslado de estudiantes y profesores al lugar del congreso otorgando, además, experiencias de vida en los estudiantes lo que contribuye a definir su opción profesional.

Desde la universidad nos hemos sumado a este desafío postulando desde la región, a diversos fondos que buscan incrementar las oportunidades de acceso vivencial con la ciencia y la tecnología a estudiantes de enseñanza básica y media. La participación de investigadores en genética humana y ancestral, genética vegetal, big data, economía regional, matemáticas y actividades de emprendimiento e innovación realizadas en el marco de campamentos escolares, sin duda, que dejan huella en quienes lo viven, sobre todo si se realiza en compañía de jóvenes de distintos colegios, comunas y regiones. Otros casos, se relacionan con el desarrollo y la transferencia de elementos educativos para colaborar con los profesores de enseñanza básica y media. Un ejemplo de esto es el uso de las herramientas ARToolKit y Vuforia de Unity para recrear mediante realidad aumentada (RA), el entorno habitacional de la comunidad ancestral "Aldea de San Lorenzo"; que habitaba el norte de Chile hace mil años. La interpretación de su hábitat levantado por arqueólogos e historiadores a partir de hallazgos materiales de la aldea, son utilizadas para recrear escenas con modelamiento en 3D y apoyo de interfaces interactivas que resultan 
de gran ayuda para incrementar en las nuevas generaciones, la valoración y protección del patrimonio cultural regional aprovechando de paso su interés por el desarrollo tecnológico de aplicaciones de este tipo. Otra opción tecnológica que ha impactado significativamente en la formación escolar es el uso de la herramienta GameMaker que es especializada para la creación de videojuegos y que contiene un motor gráfico para visualizar planos en 2D, lo que facilita la creación de juegos educativos y que pueden adaptarse en las distintas plataformas que existen hoy (computador, celular, tablet, entre otros). Con esta tecnología se levantó un videojuego que recrea el hábitat y el proceso de momificación realizada por los Chinchorro que fue un grupo de pescadores recolectores del norte de Chile que practicó la momificación artificial dos mil años antes que los egipcios. Por último, otras experiencias de intervención se relacionan con el levantamiento de ferias tecnológicas en los establecimientos educativos con apoyo de impresoras 3D, elementos de robótica de Lego; uso de plataformas como Kahoot para competencias escolares online o el diseño de estrategias educativas de matemática entretenida como elementos para contribuir a la formación de las futuras generaciones.

Actividades que desde la investigación, pueden ir indisolublemente unidos al proceso formativo; dándole un incomparable sentido de pertenencia a la ciencia y que en compañía de los elementos tecnológicos apropiados; resulta entretenida y productiva. Es aquí donde el factor de impacto medido en el aporte a la formación del capital humano regional en edades tempranas, mantiene y refuerza nuestra vocación de aportar como investigadores, a la formación de capital humano avanzado en las regiones más alejadas del centro del país.

\author{
Dra. Mónica Navarrete \\ Directora Proyecto EXPLORA Arica y Parinacota \\ Universidad de Tarapacá \\ Arica, Chile \\ monica.navarrete@gmail.com
}

